OPEN ACCESS

Edited by:

Said Dermime,

National Center for Cancer Care and

Research, Qatar

Reviewed by:

Antonio Curti,

University of Bologna, Italy

Viktor Umansky,

German Cancer Research Center

(DKFZ), Germany

${ }^{*}$ Correspondence:

Mads Hald Andersen

mads.hald.andersen@regionh.dk

Nicolai Grønne Jørgensen

nicolai.groenne.dahlager.

joergensen.01@regionh.dk

${ }^{\dagger}$ These authors have contributed equally to this work

Specialty section:

This article was submitted to

Cancer Immunity and Immunotherapy,

a section of the journal

Frontiers in Immunology

Received: 14 August 2020

Accepted: 14 October 2020

Published: 09 November 2020

Citation:

Jorgensen NG, Klausen U,

Grauslund $\mathrm{JH}$, Helleberg $C$, Aagaard TG, Do TH, Ahmad SM,

Olsen LR, Klausen TW, Breinholt MF,

Hansen M, Martinenaite E, Met Ö,

Svane $I M$, Knudsen $L M$ and

Andersen MH (2020) Peptide

Vaccination Against PD-L1

With 10103 a Novel Immune

Modulatory Vaccine in Multiple

Myeloma: A Phase I

First-in-Human Trial.

Front. Immunol. 11:595035. doi: 10.3389/fimmu.2020.595035

\section{Peptide Vaccination Against PD-L1 With I0103 a Novel Immune Modulatory Vaccine in Multiple Myeloma: A Phase I First-in-Human Trial}

Nicolai Grønne Jørgensen ${ }^{1,2 *}$, Uffe Klausen ${ }^{1,2}$, Jacob Handlos Grauslund ${ }^{1}$, Carsten Helleberg ${ }^{2}$, Thomas Granum Aagaard ${ }^{2}$, Trung Hieu Do ${ }^{2}$, Shamaila Munir Ahmad ${ }^{1}$, Lars Rønn Olsen ${ }^{3}$, Tobias Wirenfeldt Klausen ${ }^{2}$, Marie Fredslund Breinholt ${ }^{4}$, Morten Hansen ${ }^{1}$, Evelina Martinenaite ${ }^{1}$, Özcan Met ${ }^{1,5}$, Inge Marie Svane ${ }^{1}$, Lene Meldgaard Knudsen ${ }^{2 \dagger}$ and Mads Hald Andersen ${ }^{1,5 * t}$

${ }^{1}$ National Center for Cancer Immune Therapy (CCIT-DK), Department of Oncology, Copenhagen University Hospital, Herlev, Denmark, ${ }^{2}$ Department of Hematology, Copenhagen University Hospital, Herlev, Denmark, ${ }^{3}$ Department of Health Technology, Technical University of Denmark, Kgs. Lyngby, Denmark, ${ }^{4}$ Department of Pathology, Copenhagen University Hospital, Herlev, Denmark, ${ }^{5}$ Department of Immunology and Microbiology, University of Copenhagen, Copenhagen, Denmark

Background: Immune checkpoint blockade with monoclonal antibodies targeting programmed death 1 (PD-1) and its ligand PD-L1 has played a major role in the rise of cancer immune therapy. We have identified naturally occurring self-reactive T cells specific to PD-L1 in both healthy donors and cancer patients. Stimulation with a PD-L1 peptide (IO103), activates these cells to exhibit inflammatory and anti-regulatory functions that include cytotoxicity against PD-L1-expressing target cells. This prompted the initiation of the present first-in-human study of vaccination with 10103 , registered at clinicaltrials.org (NCT03042793).

Methods: Ten patients with multiple myeloma who were up to 6 months after high dose chemotherapy with autologous stem cell support, were enrolled. Subcutaneous vaccinations with 10103 with the adjuvant Montanide ISA 51 was given up to fifteen times during 1 year. Safety was assessed by the common toxicity criteria for adverse events (CTCAE). Immunogenicity of the vaccine was evaluated using IFN $\gamma$ enzyme linked immunospot and intracellular cytokine staining on blood and skin infiltrating lymphocytes from sites of delayed-type hypersensitivity. The clinical course was described.

Results: All adverse reactions to the PD-L1 vaccine were below CTCAE grade 3, and most were grade 1-2 injection site reactions. The total rate of adverse events was as expected for the population. All patients exhibited peptide specific immune responses in peripheral blood mononuclear cells and in skin-infiltrating lymphocytes after a delayedtype hypersensitivity test. The clinical course was as expected for the population. Three of 10 patients had improvements of responses which coincided with the vaccinations. 
Conclusion: Vaccination against PD-L1 was associated with low toxicity and high immunogenicity. This study has prompted the initiation of later phase trials to assess the vaccines efficacy.

Clinical Trial Registration: clinicaltrials.org, identifier NCT03042793.

Keywords: peptide, vaccination, PD-L1, first-in-human, myeloma

\section{INTRODUCTION}

The development of monoclonal antibodies that block immune checkpoint molecules (ICB) has launched a new era in the treatment of malignancies. However, ICB treatment benefits a minority of patients with cancer and is associated with side effects $(1,2)$. We have recently explored whether ICBs can also be targeted by peptide vaccination. Such a vaccine could potentially combine the low toxicity of vaccination with a therapy that mitigates cancer-imposed immune inhibition.

In preclinical studies, we have demonstrated that the ICB programmed death ligand 1 (PD-L1) is recognized by $\mathrm{T}$ cells in both healthy donors and cancer patients (3). These PD-L1-reactive $\mathrm{T}$ cells can be activated by peptide stimulation. From the signal peptide of PD-L1, we developed a highly immunogenic 19-aminoacid peptide, designated IO103. IO103-stimulated PD-L1-specific T cells are cytotoxic to cancer cell lines, including melanoma, renal cell carcinoma, breast cancer, leukemia, and chronic myeloproliferative neoplasms (4-7). In vitro stimulation with PD-L1 peptide boosted immune responses to a dendritic cell (DC) vaccine (8). Similarly, immune responses to PD-L1 have been observed in multiple myeloma (MM) (Jørgensen et al., in preparation).

In MM, T cells and natural killer (NK) cells in the tumor microenvironment exhibit upregulated PD-1, and MM cells, osteoclasts, and DCs are often PD-L1 ${ }^{+}(9-16)$. The PD-1/PDL1 pathway indirectly promotes myeloma progression by causing failure of immune control. Moreover, bone marrow (BM) stromal cells induce myeloma cells to express PD-L1, inducing increased tumor cell proliferation and reduced susceptibility to chemotherapy (17). PD-L1 expression is often detected on plasma cells in extramedullary plasmacytomas of late-stage disease (18). Furthermore, PD-1 levels on T cells in myeloma patients are negatively correlated with survival (19), and PD-L1 upregulation on MM cells is common among patients with relapsed or refractory MM and associated with an aggressive phenotype (20). However, PD-1 blockade does not exhibit single-agent activity in MM (21), and initial promising data regarding combination therapy with $\mathrm{PD}-1 \mathrm{ICB}$ and immunomodulatory drugs with dexamethasone was not confirmed in randomized trials $(22,23)$. The present study was initiated before these randomized trials were halted by the FDA in 2017.

Peptide vaccination has shown promising results in earlystage neoplasia, and combined with chemotherapy (24). Highdose chemotherapy with autologous stem cell support (HDT)mediated lymphodepletion yields a decreased Treg/CD ${ }^{+}$ratio, which theoretically should favor immunotherapy post-HDT (25, 26). Furthermore, in preclinical studies, homeostatic cytokine- driven peripheral T-cell expansion after lymphodepletion reportedly aids the establishment of antitumor responses to vaccines, prompting several studies of post-HDT immune therapy $(27,28)$. Hence, we chose to vaccinate patients as they were in post-HDT remission.

Based on previous studies of therapeutic cancer vaccines, we expected a low level of adverse reactions. The impressive preclinical immunogenicity of the peptide led us to expect the induction of strong immune responses to IO103. Here, we present the results from a phase I first-in-human study of subcutaneous vaccination with IO103 emulsified with the adjuvant Montanide.

\section{SUBJECTS AND METHODS}

\section{Study Design}

In this first-in-human open-label single-armed study, the safety and immunogenicity of vaccinations using the PD-L1 peptide IO103 with the adjuvant Montanide was evaluated. Patients were enrolled at Herlev and Gentofte University Hospital, Copenhagen, Denmark, between February and November of 2017. The study was conducted in accordance with the Helsinki Declaration, and Good Clinical Practice (GCP) recommendations. All participants gave written informed consent before enrollment. The protocol was approved by the Ethics Committee of the Capital Region of Denmark, the National Board of Health, and the Danish Data Protection Agency, and registered at www.clinicaltrials.gov (NCT03042793; date of registration: February 2, 2017). Blood samples were obtained from a reference cohort of unvaccinated patients $(n=6)$ with $\mathrm{MM}$ and who concurrently received the same standard-of-care treatment as the vaccinated patients, after they gave written informed consent in an observational study approved by the Ethics Committee of the Capital Region of Denmark (Approval no. H-17010084). In the same study, serum was sampled from patients with smoldering multiple myeloma $(\mathrm{n}=10)$.

With no previous human exposure to this vaccine to perform statistical power calculations, a sample size of 10 individuals was chosen based on experience from similar studies. Eligibility criteria included Eastern Cooperative Oncology Group performance status of $\leq 2$, no severe comorbidities or autoimmune diseases, and no signs of myeloma relapse. Cytogenetic analyses were not required. Supplementary Table 1 presents full inclusion and exclusion criteria. Patients with MM were enrolled to receive vaccination once they were in remission, between 4 weeks to 6 months post-HDT. No additional maintenance treatment was given. All patients received zoledronic acid to minimize the rate of skeletal osteolytic lesions. 


\section{Treatment}

Vaccination with a long peptide forces uptake and presentation by antigen presenting cells, whereas vaccination with short peptides (9-10 amino acids) could lead to merely coating HLA molecules. Thus, vaccination with long peptides permits inclusion of patients without HLA-type restriction, and is associated with stimulation of both $\mathrm{CD}^{+}$and $\mathrm{CD}^{+} \mathrm{T}$ cells (29). In this study, patients were administered subcutaneous vaccinations containing $100 \mu \mathrm{g}$ IO103, a 19-amino-acid peptide (FMTYWHLLNAFTVTVPKDL) from the signal peptide of PDL1 (PolyPeptide Laboratories, France). The peptide was dissolved in dimethylsulfoxide (DMSO), sterile filtered, and frozen at $-20^{\circ}$ Celsius (NUNC ${ }^{\mathrm{TM}}$ CryoTubes $^{\mathrm{TM}}$ CryoLine System ${ }^{\mathrm{TM}}$ Internal Thread, Sigma-Aldrich). At $\leq 2 \mathrm{~h}$ before administration, the peptide was thawed and dissolved in sterile water for injection. Immediately before injection, the dissolved peptide was emulsified 1:1 with the adjuvant Montanide ISA-51 (Seppic Inc. Paris, France) to a total volume of $1 \mathrm{ml}$ (30). Vaccinations were administered by subcutaneous injection every two weeks, repeated six times, and then once every 4 weeks until reaching a total of 15 vaccines.

\section{Clinical Evaluation}

Adverse events were assessed according to CTCAE v.4.03. Patients were followed with frequent blood samples including a full myeloma panel and electrocardiograms. Clinical response was evaluated following International Myeloma Working Group (IMWG) response criteria (31). Time to next treatment was calculated from autologous stem cell transplant (ASCT) until initiation of next treatment.

\section{Blood and Bone Marrow Samples}

Blood samples for isolation of serum and peripheral blood mononuclear cells (PBMCs) were obtained at baseline, after three vaccinations, after six vaccinations, and after 15 vaccinations or at relapse. Samples were kept at room temperature (RT) for $\leq 5 \mathrm{~h}$ until handling. PBMCs were isolated by gradient centrifugation of heparinized blood on Lymphoprep (STEMCELL Technologies) in LeucoSep tubes (Greiner Bio-One). Isolated PBMCs were cryopreserved in $90 \%$ human serum (Sigma-Aldrich) with 10\% DMSO (SigmaAldrich) using controlled-rate freezing (Cool-Cell, Biocision) in a $-80^{\circ} \mathrm{C}$ freezer. The next day, the ampules were transferred to $140^{\circ} \mathrm{C}$. To obtain serum samples, blood was collected in $8-\mathrm{ml}$ Vacuette gel tubes containing clot activator (Greiner Bio-One). The tubes were centrifuged, and serum was stored at $-140^{\circ} \mathrm{C}$. Serum and PBMCs were stored in 1.8-ml NUNC ${ }^{\mathrm{TM}}$ CryoTubes $^{\mathrm{TM}}$ CryoLine System $^{\text {TM }}$ Internal Thread (Sigma-Aldrich).

Heparinized bone marrow samples $(10 \mathrm{ml}$ in a heparinized tube) were obtained at baseline, after six vaccines, and after 15 vaccines or at relapse. The samples were subjected to red blood cell lysis by adding Ortho-Lysing Buffer diluted $10 \times$ in $\mathrm{H}_{2} 0$, followed by centrifugation and incubation for $15 \mathrm{~min}$ in the dark. The remaining cells were cryopreserved following the same procedure as for PBMCs.

\section{Delayed-Type Hypersensitivity and Skin- Infiltrating Lymphocytes}

Presence of tumor-specific T cells in biopsies from delayed-type hypersensitivity (DTH) testing post-vaccination is correlated with clinical outcome (32). We assessed the presence of vaccine-reactive cells at DTH sites after six vaccinations. On the lower back, we performed three intradermal injections of IO103 without adjuvant and one control injection of aqueous solvent containing DMSO without peptide. At $48 \mathrm{~h}$ post-DTH injection, skin reaction was measured, and punch biopsies were taken from the sites of IO103-containing injections and cut into fragments. Fragments were cultured in 24-well plates for 3-5 weeks in RPMI-1640 with $10 \%$ human serum and $100 \mathrm{U} / \mathrm{ml}$ interleukin-2 (IL-2) with penicillin, streptomycin, and fungizone. Three times weekly, half the medium was replaced with fresh medium containing IL-2. Skin-infiltrating lymphocytes (SKILs) emigrated from the biopsies. After 3-5 weeks, SKILs were harvested and tested in ELISPOT assays (see below). The remaining SKILs were cryopreserved, as described for PBMCs.

\section{IFN $\gamma$ ELISpot Assay}

To assess T-cell responses against IO103, indirect interferon gamma Enzyme-Linked ImmunoSPOT (IFN $\gamma$-ELISpot) assays were performed as previously described (3). PBMCs were stimulated once in vitro to increase assay sensitivity (33). Briefly, cryopreserved PBMCs were thawed and stimulated once with IO103 at RT in 24well plates with $0.5 \mathrm{ml} \mathrm{X-VIVO} \mathrm{medium.} \mathrm{After} 2 \mathrm{~h}, 1.5 \mathrm{ml} \mathrm{X-VIVO}$ medium with $5 \%$ human serum was added, and the plate was incubated at $37^{\circ} \mathrm{C}$ under $5 \% \mathrm{CO}_{2}$. The next day, IL-2 was added, yielding a concentration of $120 \mathrm{U} / \mathrm{ml}$. After 5-10 days, stimulated PBMCs were added to a 96-well nitrocellulose plate (MultiScreen, MAIP N45; Millipore) precoated with anti-IFN $\gamma$-mAb (mAb 1DIK, Mabtech, Sweden). IO103 was added, and the cells were incubated overnight. Next day, the plates were washed, biotinylated secondary anti-INF $\gamma \mathrm{mAb}$ (Mabtech) was added, and the plates were incubated for $2 \mathrm{~h}$ at RT. Then, the plates were washed, Streptavidin-enzyme conjugate (AP-Avidin; Calbiochem/ Invitrogen Life Technologies) was added, and the plates were incubated for $1 \mathrm{~h}$ at RT, and then washed again. Finally, the enzyme substrate NBT/BCIP (Invitrogen Life Technologies) was added, and the resulting spots were counted using the ImmunoSpot Series 2.0 Analyser (CTL Analyser). Maximum count was set to 500 spots/well. Raw data are available upon request.

IFN $\gamma$-ELISPOT assays on PBMCs were run in triplicate with $2.2-3.0 \times 10^{5}$ cells/well. For graphic representation, numbers were normalized to $2.2 \times 10^{5}$ cells/well. IFN $\gamma$-ELISPOT assays on SKILs were run in triplicate or quadruplicate with $3 \times 10^{5}$ cells/ well, using a reversed sequence of the $\mathrm{IO} 103$ peptide as a control. IFN $\gamma$-ELISPOT assays on BM samples were hampered by low viability and high background, but singlets were run from all time points from one patient.

\section{Flow Cytometry on PBMCs}

Cryopreserved PBMCs were thawed in wash buffer (0.5\% BSA, 2 $\mathrm{mM}$ EDTA in PBS) at $37^{\circ} \mathrm{C}$, and Fc-receptors blocked by incubation with human IgG $(20 \mathrm{mcg} / \mathrm{ml})$. PBMCs were 
stained in three panels using the following antibodies: CD3FITC, CD56-PE, CD11c-PE, CD8-PerCP, HLA-DR-PerCP, CD27-BV421, CD25-BV421, CD4-BV510, CD28-PE-Cy7, CD3-PE-Cy7, CD19-PE-Cy7, CD127-PE-Cy7, CD45RA-APC, CD56-BV510 (all from BD Bioscience, NJ, United States), CCR7-PE, PD-1-APC, CD14-BV421 (all from Biolegend, California, United States), CD16-FITC (Dako, Glostrup, Denmark), and NiR live-dead reagent for APC-Cy7 channel (Invitrogen-Thermo Fischer, United States). Two panels for analyzing regulatory $\mathrm{T}$ cells (Tregs) were run: one with intracellular FoxP3-PE and one with only surface markers, including CCR7-PE. Both Treg panels included CD45RAFITC, CD4-PerCP, CD127-PE-Cy7, CCR4-APC, CD25BV421, and CD15s-BV510. Samples were incubated with relevant antibodies for $20 \mathrm{~min}$ in the dark at $4^{\circ} \mathrm{C}$, washed, and then analyzed on a FACS Canto II flow cytometer (BD) and analyzed using FACSDiva Software version 8.0.1 (BD). T cells in the CD4 and CD8 compartments were characterized by examining live singlet events in the PBMC (lymphocyte and monocyte) gate in the forward and side scatter plot. Naïve T cells were characterized as $\mathrm{CCR} 7^{+} \mathrm{CD} 45 \mathrm{RA}^{+}$, central memory $(\mathrm{CM})$ as $\mathrm{CCR}^{+} \mathrm{CD}^{2} 5 \mathrm{RA}^{-}$, effector memory as $\mathrm{CCR7}^{-} \mathrm{CD}^{-} 5 \mathrm{RA}^{-}$, and effector memory $\mathrm{RA}^{+}$(EMRA) as $\mathrm{CCR7}^{-} \mathrm{CD} 45 \mathrm{RA}^{+}$. Tregs were gated on PBMCs, singlets, live cells, and subsequently on $\mathrm{CD} 4^{+}$ cells. Supplementary Figure 10 presents the gating strategy for Tregs. Myeloid DCs $\left(\mathrm{LIN}^{-} \mathrm{CD} 11 \mathrm{c}^{+} \mathrm{HLA}-\mathrm{DR}^{+} \mathrm{CD} 14^{-} \mathrm{CD} 16^{-}\right)$and non-classical monocytes $\left(\mathrm{LIN}^{-} \mathrm{CD} 11 \mathrm{c}^{+} \mathrm{HLA}-\mathrm{DR}^{+} \mathrm{CD} 14^{-} \mathrm{CD} 16^{+}\right.$) were gated from the Lineage (CD3/CD19/CD56) and CD14 negative and CD11c, HLA-DR positive fraction of PBMCs. To analyze SKILs' cytokine secretion capability, intracellular cytokine staining was performed on SKILs incubated $5 \mathrm{~h}$ with or without $5 \mu \mathrm{g} / \mathrm{ml} \mathrm{IO} 103\left(37^{\circ} \mathrm{C}, 5 \% \mathrm{CO}_{2}\right)$. GolgiPlug (BD) was applied before staining with CD3-APC-H7, CD4-PerCP/FITC, CD8-Pacific Blue/PerCP, and Horizon Fixable Viability Stain 510 (BD). The cells were fixed and permeabilized with Fixation/ Permeabilization Buffer (eBioscience), following the manufacturer's instructions, and then intracellularly stained using IFN $\gamma$-PE-Cy7/APC (eBioscience) and TNF-APC/BV421 (eBioscience). Relevant isotype controls were used to support correct compensation and confirm antibody specificity.

\section{Cytokines in Serum}

Cytokines in serum samples were measured using the MSD Mesoscale V-Plex Human Cytokine 30-plex Kit (Catalog No. K15054D-1), following the manufacturer's instructions, except that the samples were diluted four-fold instead of two-fold.

\section{Statistical Analysis}

Responses in ELISpot assays were determined using the previously described distribution-free resampling (DFR) method as described by Moodie et al. (34). The Wilcoxon matched-pairs signed-rank test was used to compare responses to IO103 between baseline and later time points. For flow cytometry samples, the unpaired Mann-Whitney was used to compare lymphocyte subsets in vaccinated patients versus the reference cohort at an individual time point. As this exploratory analysis was descriptive and done post hoc, no formal multiple testing corrections were performed. $p$ values $\leq 0.05$ were considered significant. All analyses were performed in Graphpad Prism v 8.0 (GraphPad Software. Inc.).

For cytokine heatmaps each protein/cytokine was normalized by subtracting the mean value and dividing by standard deviation of the logarithmic transformed values. The normalized values for the cytokines for each subject were

TABLE 1 | Patient characteristics.

\begin{tabular}{|c|c|c|c|c|c|c|c|c|c|}
\hline & Age & Sex & $\begin{array}{l}\text { ECOG } \\
\text { PS }\end{array}$ & Comorbidity & $\begin{array}{c}\text { Type of } \\
\text { paraprotein }\end{array}$ & $\begin{array}{l}\text { LDH at } \\
\text { diagnosis }\end{array}$ & $\begin{array}{l}\text { Cytogenetics at } \\
\text { diagnosis }\end{array}$ & $\begin{array}{l}\text { ISS/R-ISS at } \\
\text { diagnosis }\end{array}$ & $\begin{array}{c}\text { Time from } \\
\text { HDT } \\
\text { to start of } \\
\text { vaccination } \\
\text { (days) }\end{array}$ \\
\hline Patient 1 & 70 & $\mathrm{~F}$ & 0 & Hypertension, Cholecystectomy & Lambda & 262 & Not enough material & $2 / 2$ & 188 \\
\hline Patient 2 & 69 & $\mathrm{M}$ & 0 & $\begin{array}{l}\text { Hypertension, } \\
\text { Hypercholesterolemia, CABG, } \\
\text { BCC }\end{array}$ & Kappa & 188 & $\begin{array}{l}\text { amp1q(80\%), t(11:14) } \\
(100 \%)=\text { High risk }\end{array}$ & $1 / 1$ & 70 \\
\hline Patient 3 & 58 & $\mathrm{~F}$ & 1 & Hypertension, multinodular goiter & Lambda & 246 & $\begin{array}{l}\text { Normal FISH = Standard } \\
\text { risk }\end{array}$ & $3 / 3$ & 131 \\
\hline Patient 4 & 58 & $\mathrm{M}$ & 1 & None & IgG kappa & 172 & $\begin{array}{l}\mathrm{t}(11: 14)(91 \%)=\text { Standard } \\
\text { risk }\end{array}$ & $3 / 2$ & 43 \\
\hline Patient 5 & 60 & $\mathrm{~F}$ & 1 & Inguinal hernea & Lambda & 141 & $\begin{array}{l}\mathrm{t}(11: 14)(96 \%)=\text { Standard } \\
\text { risk }\end{array}$ & $3 / 3$ & 61 \\
\hline Patient 6 & 59 & M & 1 & None & lgG kappa & 220 & $\begin{array}{l}\text { del(13q14.3)(96\%) del1p } \\
(97 \%)=\text { High risk }\end{array}$ & $1 / 2$ & 82 \\
\hline Patient 7 & 60 & $\mathrm{~F}$ & 1 & $\begin{array}{l}\text { Hypertension, Spinal stenosis } \\
\text { operata }\end{array}$ & lgG kappa & 260 & Not enough material & $3 / 2$ & 41 \\
\hline Patient 8 & 61 & M & 1 & None & $\begin{array}{l}\text { Biclonal lgG kappa } \\
\text { lgA kappa }\end{array}$ & 142 & Not enough material & $2 / 2$ & 50 \\
\hline Patient 9 & 69 & M & 1 & None & lgG kappa & 175 & Not done & Missing & 28 \\
\hline Patient 10 & 39 & M & 1 & None & lgG kappa & 148 & Not possible & $2 / 2$ & 83 \\
\hline
\end{tabular}

Patient 9 had previously been transplanted, and was enrolled after a HDT treating first relapse.

HDT, high dose chemotherapy with autologous stem cell transplant; ISS, International Staging System; LDH, lactate dehydrogenase. 
shown in the heatmap. The dendrograms and ordering of subjects and cytokines were performed by hierarchical clustering using Ward's method. Distances between cytokines were calculated by $1-\mathrm{r}$, where $\mathrm{r}$ is the Pearson correlation coefficient and distances between subjects by Euclidian distance. The R function "agnes" in the "cluster" package was used for clustering.

\section{RESULTS}

\section{Patient Characteristics}

Our study population included 10 patients with MM (4 female and 6 male; mean age, 60.3 years; age range: $39-70$ ), who had undergone HDT treatment within 1-6 months. Table 1 shows patient characteristics. Nine patients were included after firstline induction therapy with HDT. Induction therapy comprised standard of care therapy of cyclophosphamide, bortezomib, and dexamethasone (Cy-Vel-Dex) for all but one patient who instead received bortezomib, thalidomide, and dexamethasone (VTD, patient 4) due to renal insufficiency at diagnosis. Patient 9 was included after Cy-Vel-Dex and HDT, following relapse occurring 18 years after primary double transplantation. Five patients lacked cytogenetic data from diagnosis. FISH was performed on BM samples at inclusion, but the low tumor burden postHDT prohibited cytogenetic analysis. All included patients received at least 6 vaccines and are included in the data set.

\section{Adverse Events}

Infections are common in patients with $\mathrm{MM}$, and the infection rate is further increased for at least one1 year post-HDT. The rate of infections and other adverse events was as expected for the population (Table 2). Adverse events considered potentially related to vaccination were most commonly injection site reactions and were all transient of nature (Table 2). No adverse events above grade 2 were deemed related to the vaccine. No autoimmune adverse events were observed.

\section{Immune Responses in Blood}

PBMCs from blood samples were assessed using indirect ELISPOT assays against IO103. No or little response to the vaccine occurred at baseline, while all patients exhibited a response to IO103 during the vaccination course (Figures 1AD). To assess whether immune responses to IO103 would normally occur post-HDT, we ran IO103 ELISPOT on our reference cohort at similar time points as in the vaccinated patients. Consistent with our previous data, we observed spontaneous immune responses to IO103 before HDT. These responses were not observed post-HDT in the unvaccinated reference cohort (Figure 1E), likely due to the strong lymphodepleting chemotherapy.

\section{Immune Responses in the Skin}

Nine patients consented to DTH testing before the seventh vaccine. The cells from one patient (patient 3) were accidentally infected in culture. All eight evaluable patients had
TABLE 2 | AEs total adverse events during vaccinations

\begin{tabular}{|c|c|c|c|c|c|}
\hline Relation to therapy* & Adverse event & $\begin{array}{c}\text { No. of } \\
\text { patients }\end{array}$ & $\begin{array}{c}\text { Grade } \\
1\end{array}$ & $\begin{array}{c}\text { Grade } \\
2\end{array}$ & $\begin{array}{c}\text { Grade } \\
3\end{array}$ \\
\hline \multirow{23}{*}{$\begin{array}{l}\text { Cy-Vel-Dex induction, } \\
\text { HDT, myeloma or } \\
\text { unrelated }\end{array}$} & Cold & 6 & 6 & & \\
\hline & $\begin{array}{l}\text { Respiratory } \\
\text { tract infection }\end{array}$ & 3 & 1 & & 2 \\
\hline & Influenza & 2 & & 1 & 1 \\
\hline & $\begin{array}{l}\text { Urinary tract } \\
\text { infection }\end{array}$ & 2 & & 2 & \\
\hline & Abscessus & 1 & & 1 & \\
\hline & Conjunctivitis & 1 & & 1 & \\
\hline & $\begin{array}{l}\text { Fungal skin } \\
\text { infection }\end{array}$ & 1 & & 1 & \\
\hline & $\begin{array}{l}\text { Flu-like viral } \\
\text { infection }\end{array}$ & 1 & & 1 & \\
\hline & Gastroenteritis & 1 & & 1 & \\
\hline & $\begin{array}{l}\text { Herpes } \\
\text { reactivation }\end{array}$ & 1 & & 1 & \\
\hline & Sinusitis & 1 & & 1 & \\
\hline & Tonsillitis & 1 & & & 3 \\
\hline & Cough & 2 & 2 & & \\
\hline & Diarrhoea & 2 & 2 & & \\
\hline & $\begin{array}{l}\text { Basal cell } \\
\text { carcinoma }\end{array}$ & 1 & & & 1 \\
\hline & Constipation & 1 & 1 & & \\
\hline & $\begin{array}{l}\text { Creatinin } \\
\text { increase }\end{array}$ & 1 & 1 & & \\
\hline & Hernia, inguinal & 1 & & & 1 \\
\hline & Nausea & 1 & & 1 & \\
\hline & Palpitations & 1 & & 1 & \\
\hline & Sore throat & 1 & 1 & & \\
\hline & $\begin{array}{l}\text { Tendernes of } \\
\text { jaw }\end{array}$ & 1 & 1 & & \\
\hline & $\begin{array}{l}\text { Artroscopic } \\
\text { miniscus } \\
\text { manipulation }\end{array}$ & 1 & & & 1 \\
\hline \multirow[t]{11}{*}{ PD-L1 vaccine (IO103) } & $\begin{array}{l}\text { Injection site } \\
\text { reaction }\end{array}$ & 9 & 6 & 3 & \\
\hline & Pruritus & 3 & 2 & 1 & \\
\hline & Myalgia & 3 & 1 & 2 & \\
\hline & Artralgia & 2 & & 2 & \\
\hline & Sore nipple & 2 & 2 & & \\
\hline & Dry skin & 1 & 1 & & \\
\hline & Lymphopenia & 1 & 1 & & \\
\hline & Cough & 1 & 1 & & \\
\hline & Dermatitis & 1 & & 1 & \\
\hline & Rash & 2 & 1 & 1 & \\
\hline & $\begin{array}{l}\text { Swelling of } \\
\text { bursa olecrani }\end{array}$ & 1 & 1 & & \\
\hline
\end{tabular}

*Investigator deemed whether adverse events were related or possibly related to the experimental treatment or to other causes. Injection site reactions included local erythema oedema, and pruritus. Non-tender subcutaneous lumps up to $1 \mathrm{~cm}$ in diameter could linger up to months, as is seen commonly with the deposition of the adjuvant Montanide. Cy-Vel-Dex, cyclophosphamide-bortezomib-dexamethazone; HDT, high-dose chemotherapy with autologous stem cell transplantation.

a positive skin induration of more than double the diameter of the control injection. SKILs could be grown from skin biopsies of all patients, and all were strongly reactive to the vaccine as evaluated by IFN $\gamma$-ELISPOT (Figure 2A). IL2-expanded SKILs were mainly $\mathrm{CD}^{+} \mathrm{T}$ cells (data not shown). Intracellular cytokine staining after stimulation with $\mathrm{IO} 103$ revealed that these $\mathrm{CD} 4^{+}$SKILs secreted tumor necrosis factor alfa (TNF- $\alpha$ ) and a minor fraction also secreted IFN- $\gamma$ (Figures 2B, C). 
A

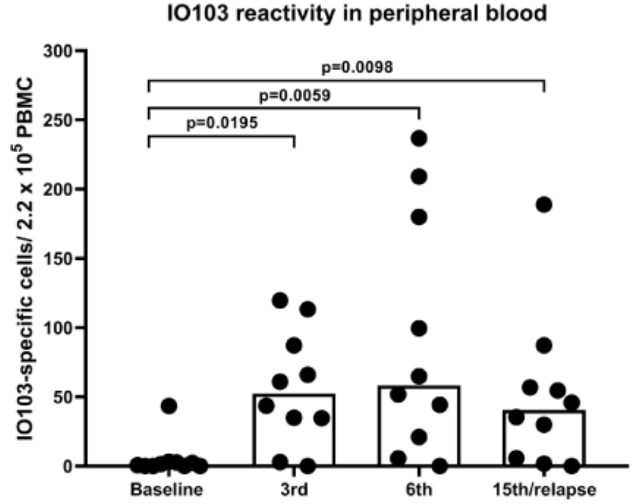

C

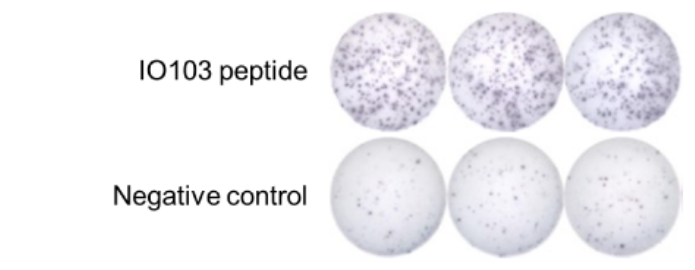

E

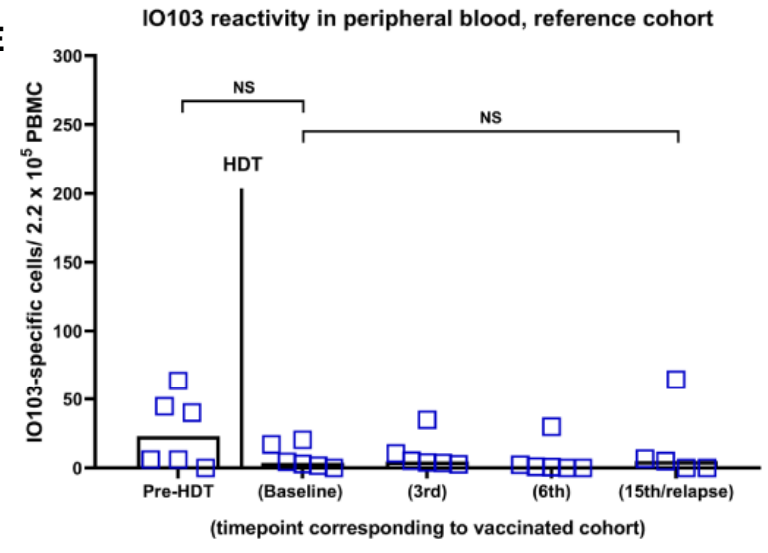

B

10103-specific cells in peripheral blood per $2.2 \times 10^{5}$ cells

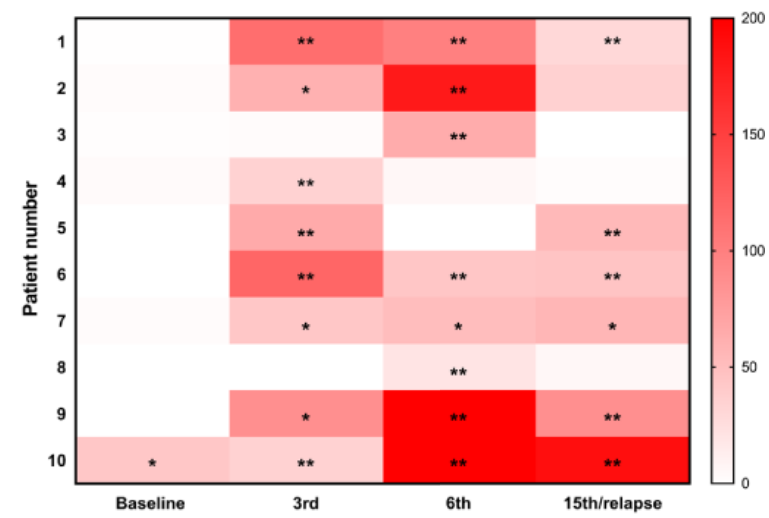

D

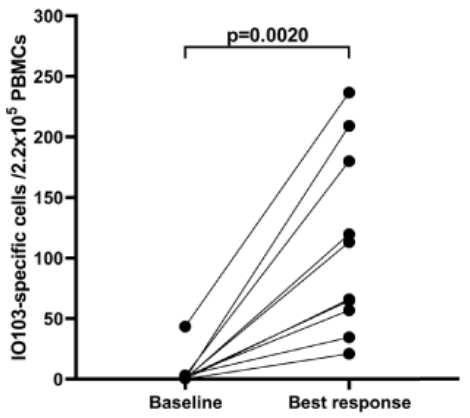

$\mathbf{F}$

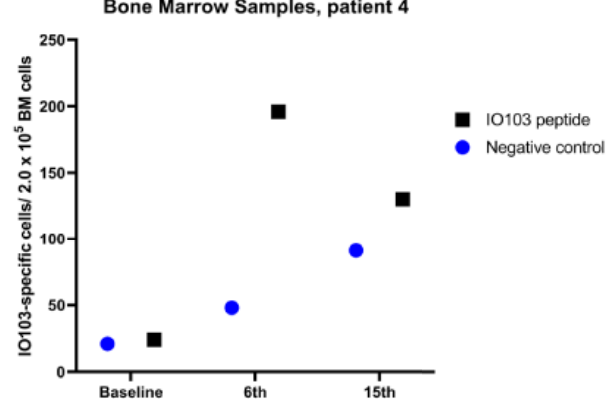

FIGURE 1 | IFNy-ELISPOT immune responses against IO103. (A) responses in PBMCs in vaccinated patients (bars represent median); (B) Heatmap of responses in PBMCs per vaccinated per time point. ('DFRx1; **DFRx2); (C) representative example of ELISPOT-wells with response; (D) best response in PBMCs in vaccinated patients; (E) responses in unvaccinated reference cohort including time point before HDT (All p-values: Wilcoxon matched-pairs signed rank test); (F) IFN $\gamma$-ELISPOT responses against IO103 in bone marrow samples from patient 4.

\section{Immune Responses in the Bone Marrow}

ELISPOT assays on cryopreserved BM samples had a very high background signal due to ex vivo cell death. Reduced viability of BM mononuclear cells is well known (35). The fact that these BM samples were taken in the recovery from HDT, may have decreased the viability further. The low viability of the immune cells in the BM samples did not permit in depth immune monitoring with functional living cells. Nonetheless, singlet samples were run with only modest background in one of three tested patients, and in samples from this patient, a strong immune response to IO103 was seen in the BM (Figure 1F).

\section{Lymphocytes}

An exploratory analysis of lymphocyte phenotypes was performed comparing samples from the vaccinated patients to samples from the unvaccinated reference cohort. Vaccinated patients 1, 3, 6, and 10 were not included in these comparisons, since these patients did not have synchronous reference cohort samples for comparison. An inversion of the CD4/CD8 ratio following HDT was seen in the unvaccinated cohort, and the vaccinated patients had a similar ratio at baseline (Supplementary Figures 1A, B). A significantly lower level of $\mathrm{CD} 4$ cells in vaccinated patients after $15^{\text {th }}$ vaccination or relapse 
A
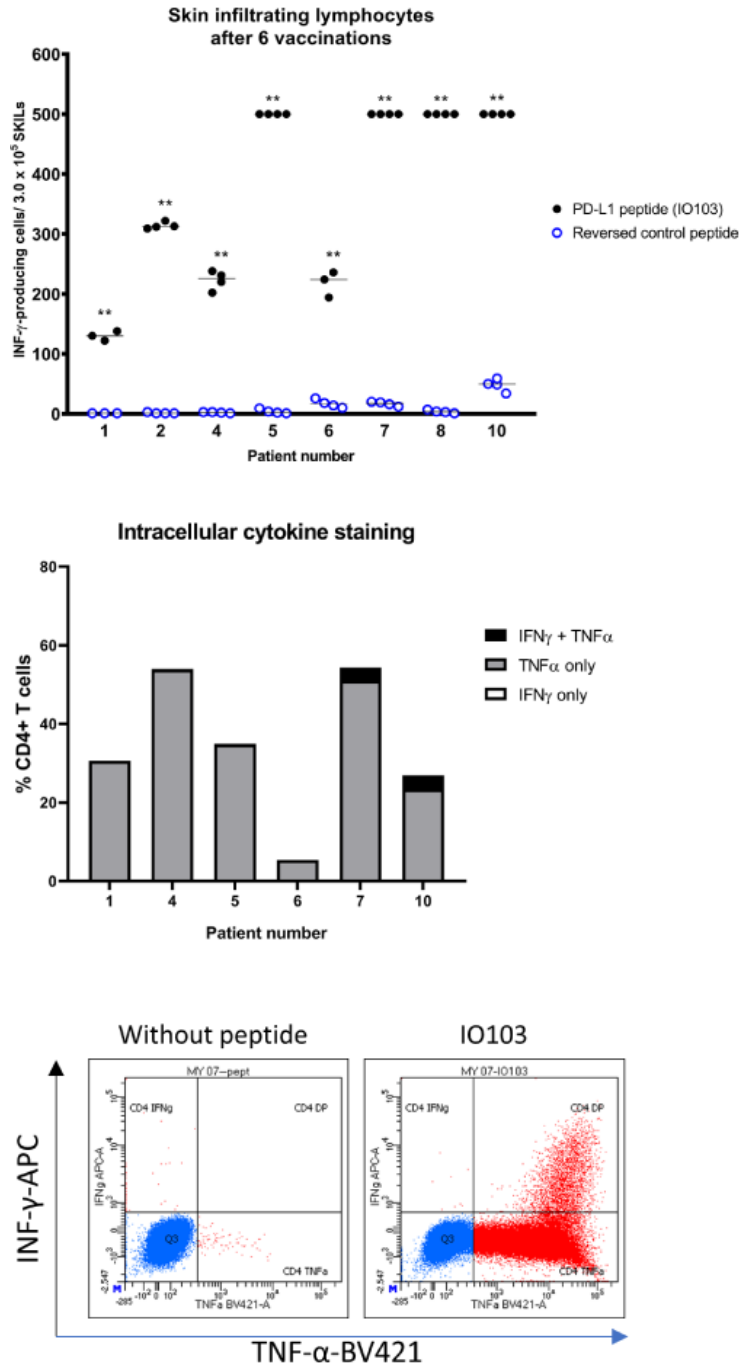

FIGURE 2 | Immune responses to the vaccine in the skin. (A) IFN $\gamma$-ELISPOT responses against the PD-L1 peptide 10103 of skin infiltrating lymphocytes after delayed type hypersensitivity reaction performed after 6 vaccines. 300,000 cells per well. Samples were run in triplicate or quadruplicate. ${ }^{*}$ DFRx2; (B) intracellular cytokine staining (ICS) of SKILs. Almost all cells were CD4+ (not shown). Two out of six evaluable patients had TNF $\alpha$ - and INF $\gamma$ double positive SKILs; (C) example of a double positive ICS (patient 7).

was seen. Gating of differentiation stages did not reveal significant differences and exhibited substantial interindividual variance. Naïve cell repopulation post-HDT did not significantly differ in samples from vaccinated patients compared to the reference population (Supplementary Figures 2 and 3). The level of Tregs was not found to be significantly different compared to the reference population (Figures 3A-D). The FoxP3 $^{+}$Treg levels of all vaccinated patients are shown in Supplementary Figure 12. Levels of DCs in peripheral blood samples did not show significant differences compared to the reference population (Supplementary Figure 13).

\section{Clinical Course}

Before vaccinations, four patients were in complete response (CR) or better, and five had very good partial response (VGPR). At the data cut-off (May 14, 2020; mean follow-up, 36.5 months), $2 / 10$ patients had not started their next treatment, and 8/10 were still alive (Supplementary Figure 4). The relapse rate was as expected for the population.

Three patients exhibited improved depth of response during vaccination therapy: patient 2 at day 145 post-ASCT (after 5 vaccines), patient 5 at day 161 (6 vaccines), and patient 7 at day 168 (7 vaccines) (Figure 4).

Patients 3 and 7 showed declining levels of M component/ involved light chain during vaccinations; however, both exhibited slow biochemical relapse after completing vaccinations. As a study amendment, these two patients were revaccinated to test if a stabilization or decline could be induced. In patient 3, revaccination did not decrease the tumor marker slope (Supplementary Figure 7). In patient 7, the M-component slope decreased briefly along with revaccinations (Supplementary Figure 8).

Patient 8 exhibited an early rapid clinical relapse, which was fatal despite initiation of therapy with daratumumab, lenalidomide, and dexamethasone. At this time, the patient had received 11 vaccines. We explored possible correlations between immune data and clinical course. Patients who did and did not relapse during the vaccination course did not differ in ELISPOT responses to IO103 in blood samples (Supplementary Figure 5). However, the two earliest relapsing patients (patients 8 and 9) showed baseline cytokine profiles that grouped apart from the remaining vaccinated patients in unsupervised analysis (Supplementary Figures 6A, B). Furthermore, two patients (patients 8 and 4) with early relapses had the lowest ELISPOT responses to IO103 in PBMCs (Figure 1C), and the highest Treg levels in PBMCs even at baseline (Supplementary Figure 11).

During the vaccination course, patient 2 exhibited significant regression of concurrent basal cell carcinoma (BCC), and patient 6 exhibited spontaneous BCC clearance that was macroscopically complete, such that planned surgery was cancelled. In patient 6 , BCC recurred, coinciding with biochemical relapse of MM.

\section{DISCUSSION}

The vaccine was generally well tolerated, and the frequency of adverse events was as expected in the patient population. Adverse events that were related or possibly related to vaccination with $\mathrm{IO} 103$ were mild (CTCAE grade 1-2) and reversible, and most frequently injection site reactions.

$\mathrm{PD}-\mathrm{L} 1$ is expressed on cancer cells and non-cancerous cells in the tumor microenvironment, on normal antigen-presenting cells and placental cells, and frequently on cells in an inflammatory microenvironment, since its expression is primarily regulated by interferons (36). We recently demonstrated that inflammation alone induces PD-L1-specific T cells (37). The fact that PD-L1-specific T cells are so easily and rapidly activated, but do not lead to outright autoimmune 
A

FoxP $3^{+}$Treg

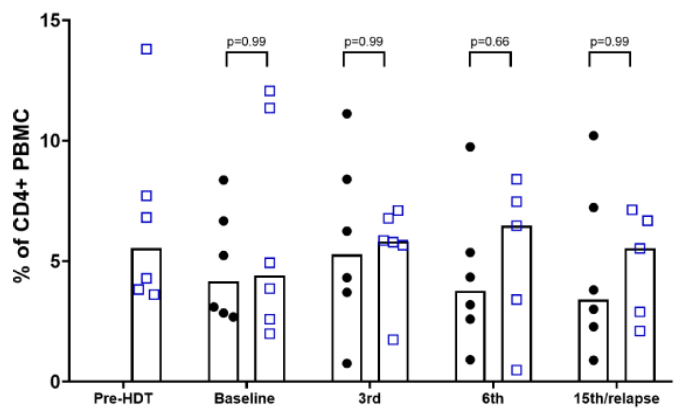

C

\section{$\mathrm{CCR}^{+}$Primed Treg}

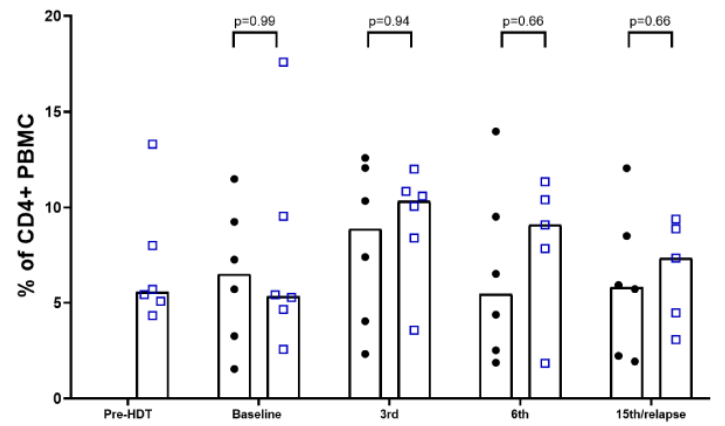

B

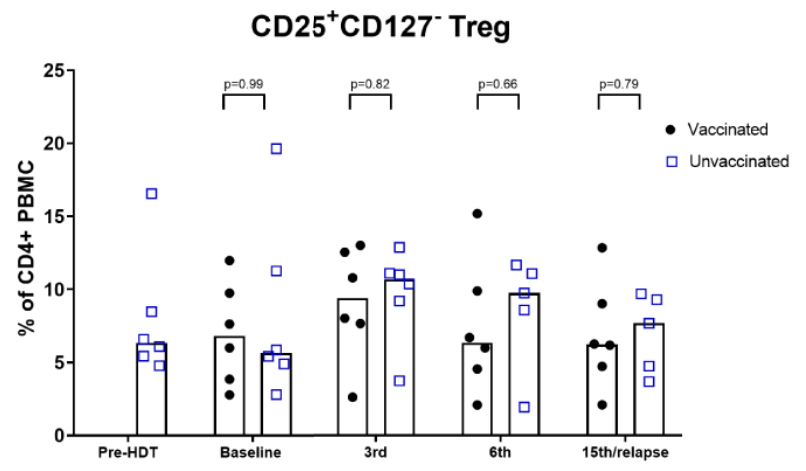

D

\section{$\mathrm{CD}{ }^{+} \mathrm{s}^{+}$Effector Treg}

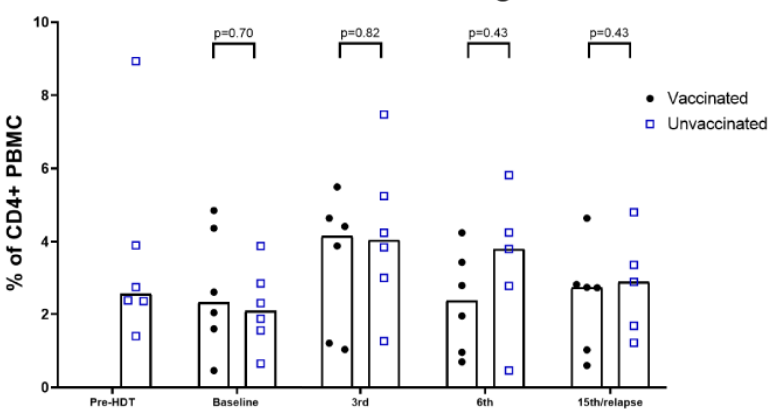

FIGURE 3 | Flow cytometric analyses of levels of Tregs. (A) FoxP3+ Treg. (B) CD25highCD127neg Treg; (C) CCR4 + Primed Tregs; (D) CD15s Effector Tregs. \% of CD4+ PBMCs. Bars represent median (Mann-Whitney).

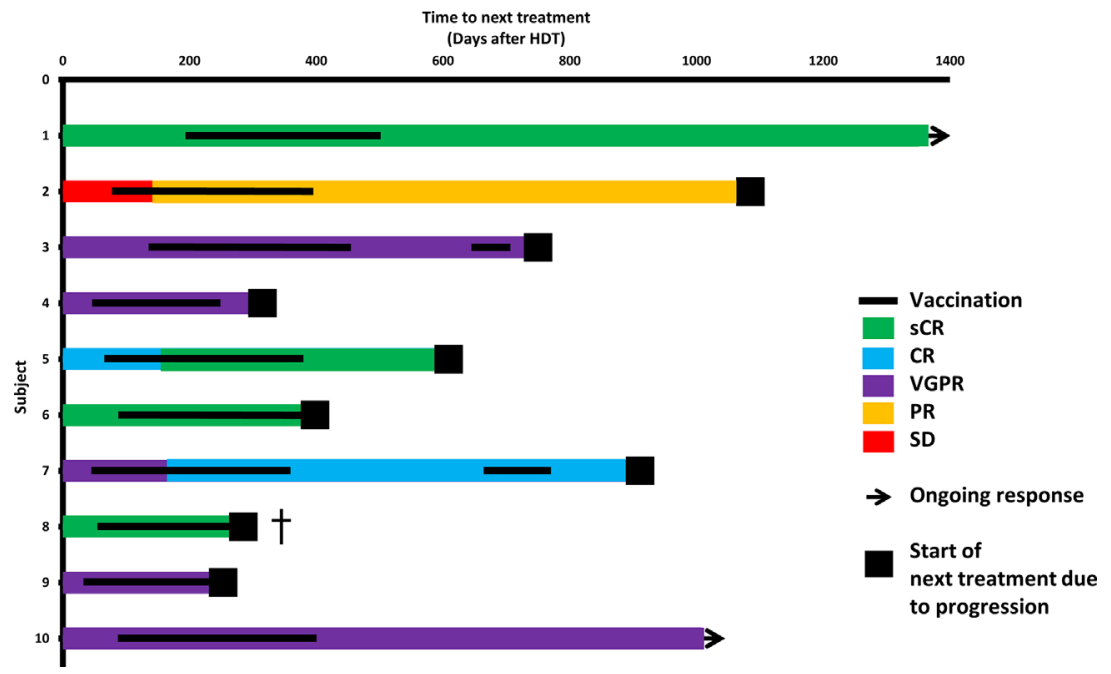

FIGURE 4 | Clinical course. Swimmer's plot. Colors of bars symbolize depth of response at start of vaccinations, after HDT and during the vaccination course. ${ }^{\dagger}$ patient 8 had a rapid relapse after having received 11 vaccinations and died shortly thereafter despite initiation of daratumumab-lenalidomide-dexamethasone. 
reactions, implies that these cells are strictly regulated. Mouse studies of vaccination with murine PD-L1 peptides confirm the absence of signs of autoimmune events (in preparation). In this first-in-human study, we observed immune reactions to the vaccine in blood samples and skin tests from all patients. It is intriguing that stimulation of these self-reactive $\mathrm{T}$ cells strongly induced immune responses in all patients, with low toxicity.

In the months following lymphodepleting chemotherapy in $\mathrm{HDT}, \mathrm{CD}^{+}$T-cell repopulation is aided by homeostatic peripheral expansion more than the $\mathrm{CD}^{+}$compartment, yielding a relatively low Treg/ $\mathrm{CD} 8^{+}$ratio, which gradually normalizes as levels return to baseline (25). An inverted ratio of $\mathrm{CD}^{+} / \mathrm{CD}^{+} \mathrm{T}$ cells was found in both vaccinated patients and the unvaccinated reference cohort. In preclinical studies, activation of $\mathrm{PD}-\mathrm{L} 1-$ specific $\mathrm{T}$-cells reduced Treg levels in autologous PBMCs (37). Vaccination against an indoleamine 2,3-dioxygenase (IDO) peptide in patients with lung cancer similarly induced a significant decrease in Tregs (38). IDO is another self-antigen expressed in regulatory immune cells, which is recognized by pro-inflammatory T cells $(39,40)$. In the present study, although the proportion of $\mathrm{CD}^{+} \mathrm{T}$ cells was lower in vaccinated patients at the last time point, the levels of Tregs was not significantly lower among vaccinated patients at any time point. This study setting might not permit the assessment of the vaccine's effect on Treg levels, due to the recently been exposure to lymphodepleting chemotherapy.

Antigen presenting cells at the vaccination site may be PD-L1 positive. Thus, vaccination induced elimination of these cells could impact antigen presentation at the vaccination site. However, analysis of DC infiltration at the vaccination site was not been performed in this study but will be part of future investigations. Importantly, no signs of a major effect of vaccinations were seen on the frequencies of DC in peripheral blood.

One limitation of this study was our inability to thoroughly investigate immune responses in $\mathrm{BM}$ samples. Since $\mathrm{MM}$ is a disease of BM-residing cells, one would hope to see an immune response in the BM. However, the viability of $\mathrm{BM}$ samples precluded other functional assays of BM immune cells, and assessment of immune responses at the tumor site. These limitations led us to instead analyze the impact of vaccinations on T-cell-receptor (TCR) diversity in SKILs and BM samples, including PD-L1-specific TCRs. These studies are currently on-going.

The current study was valuable for examining the vaccine's safety. The minimal tumor burden post-HDT allowed us to vaccinate many times, over a prolonged period. Phase one studies are often performed in the relapsed or refractory setting, which would likely not leave sufficient time to test the vaccine's safety before disease progression. One downside of the post-HDT setting is that clinical efficacy was difficult to investigate. Nine patients were vaccinated post-HDT as part of primary treatment of newly diagnosed MM. In this patient population, median progression-free survival without maintenance treatment is 32 months, and $20 \%$ of patients will be in long-term remission (6 years post-HDT) (41). With a median follow-up of 29 months, the PFS data are not yet mature.
In a Mayo Clinic study, response improvements after day +100 occurred in up to $39 \%$ of cases (42). However, among patients treated in Barcelona and Salamanca, only 1/74 patients had an upgraded response after day 100 without maintenance or consolidation (43). Response improvements beyond day 100 rarely occur at our institution (personal communication), and late improvements have been used as an argument regarding response to immunotherapy after HDT (12). The three late response improvements (over 100 days post-HDT), and one case of short-term stabilization coinciding with revaccination, may indicate the vaccine's efficacy.

The incidental findings of spontaneous BCC regression in patients 2 and 6 are interesting. After the initial spontaneous BCC clearance, patient 6 experienced clinical relapse of BCC coinciding with biochemical relapse of MM. This suggests that the vaccine induced a response toward the BCC, which lasted for months, and then experienced a loss of immune control affecting both malignancies once the vaccination was no longer effective. This cannot be tested with current methods but has prompted the initiation of a phase IIa study of vaccination with IO103 in BCC (NCT03714529).

Based on the present promising safety and immune data, several clinical trials have been initiated. It is hypothesized that therapeutic cancer vaccines, without chemotherapy or ICB, are likely to be most effective if administered in early disease stages $(44,45)$. Thus, a trial of IO103 in high-risk smoldering myeloma has been initiated (NCT03850522). Additionally, we are testing this vaccine combined with other peptide vaccines against $\mathrm{PD}$ L2, IDO, and arginase, and with immune checkpoint-blocking antibodies (NCT03381768, NCT03939234, and NCT04051307).

In conclusion, the vaccination against $\mathrm{PD}-\mathrm{L} 1$ was easily administered and was associated with few and low-grade and reversible side effects. Furthermore, the vaccine induced strong immune responses in all patients.

\section{DATA AVAILABILITY STATEMENT}

The raw data supporting the conclusions of this article will be made available by the authors, without undue reservation.

\section{ETHICS STATEMENT}

The studies involving human participants were reviewed and approved by De Videnskabsetiske Komiteer i Region Hovedstaden. The patients/participants provided their written informed consent to participate in this study.

\section{AUTHOR CONTRIBUTIONS}

NJ designed the study, obtained institutional approval, performed the research, analyzed data, and wrote the manuscript. UK, JG, $\mathrm{CH}$, $\mathrm{TA}$, and TD recruited and treated the patients and critically revised the manuscript. SA, MB, EM, and ÖM performed laboratory 
research and critically revised the manuscript. $\mathrm{LO}, \mathrm{TK}$, and $\mathrm{MH}$ assisted in the data analysis and critically revised the manuscript. IS, LK, and MA conceptualized the study, designed the study, supervised the project, and critically revised the manuscript. All authors contributed to the article and approved the submitted version.

\section{FUNDING}

The work was funded by The Danish Cancer Society, The Copenhagen University Hospital Herlev and Gentofte, and through a research funding agreement between IO Biotech ApS and National Center for Cancer Immune Therapy (CCIT-DK).

\section{REFERENCES}

1. Bedognetti D, Ceccarelli M, Galluzzi L, Lu R, Palucka K, Samayoa J, et al. Toward a comprehensive view of cancer immune responsiveness: A synopsis from the SITC workshop. J Immunother Cancer (2019) 7:1-23. doi: 10.1186/ s40425-019-0602-4

2. Naidoo J, Page DB, Li BT, Connell LC, Schindler K, Lacouture ME, et al. Toxicities of the Anti-PD-1 and Anti-PD-L1 Immune Checkpoint Antibodies. Ann Oncol (2015) 26:2375-91. doi: 10.1093/annonc/mdv383

3. Munir S, Andersen GH, Met Ö, Donia M, Frøsig TM, Larsen SK, et al. HLArestricted CTL that are specific for the immune checkpoint ligand PD-L1 occur with high frequency in cancer patients. Cancer Res (2013) 73:1764-76. doi: 10.1158/0008-5472.CAN-12-3507

4. Munir S, Andersen GH, Woetmann A, Ødum N, Becker JC. Andersen MH.Cutaneous $\mathrm{T}$ cell lymphoma cells are targets for immune checkpoint ligand PD-L1-specific, cytotoxic T cells. Leukemia (2013) 27:2251-2253. doi: 10.1038/leu.2013.118

5. Ahmad SM, Larsen SK, Svane IM, Andersen MH. Harnessing PD-L1-specific cytotoxic T cells for anti-leukemia immunotherapy to defeat mechanisms of immune escape mediated by the PD-1 pathway. Leukemia (2013) 28:236-8. doi: 10.1038/leu.2013.261

6. Holmström MO, Riley CH, Skov V, Svane IM, Hasselbalch HC. Andersen MH.Spontaneous $\mathrm{T}$-cell responses against the immune check point programmed-death-ligand 1 (PD-L1) in patients with chronic myeloproliferative neoplasms correlate with disease stage and clinical response. Oncoimmunology (2018) 7:1-6. doi: 10.1080/2162402X.2018.1433521

7. Munir S, Andersen GH, Svane IM, Andersen MH. The immune checkpoint regulator PD-L1 is a specific target for naturally occurring CD4(+) T cells. Oncoimmunology (2013) 2:e23991. doi: 10.4161/onci.23991

8. Munir Ahmad S, Martinenaite E, Hansen M, Junker N, Borch TH, Met Ö, et al. PD-L1 peptide co-stimulation increases immunogenicity of a dendritic cell-based cancer vaccine. Oncoimmunology (2016) 5:e1202391. doi: 10.1080/ 2162402X.2016.1202391

9. Benson DM, Bakan CE, Mishra A, Hofmeister CC, Efebera Y, Becknell B, et al. The PD-1 / PD-L1 axis modulates the natural killer cell versus multiple myeloma effect : a therapeutic target for CT-011, a novel monoclonal anti PD-1 antibody. Blood (2010) 116:2286-94. doi: 10.1182/blood-2010-02271874

10. Liu J, Hamrouni A, Wolowiec D, Coiteux V, Kuliczkowski K, Hetuin D, et al. Plasma cells from multiple myeloma patients express B7-H1 (PD-L1) and increase expression after stimulation with IFN- $\gamma$ and TLR ligands via a MyD88-, TRAF6-, and MEK-dependent pathway. Blood (2007) 110:296304. doi: 10.1182/blood-2006-10-051482

11. Hallett WHD, Jing W, Drobyski WR, Johnson BD. Immunosuppressive Effects of Multiple Myeloma Are Overcome by PD-L1 Blockade. Biol Blood Marrow Transplant (2011) 17:1133-45. doi: 10.1016/j.bbmt.2011.03.011

12. Rosenblatt J, Avivi I, Vasir B, Uhl L, Munshi NC, Katz T, et al. Vaccination with dendritic cell/tumor fusions following autologous stem cell transplant

\section{ACKNOWLEDGMENTS}

We greatly appreciate the tremendous technical support from Merete Jonassen, Sandra Ullitz Færch, Betina Saxild, Susanne Wendt, and Kirsten Nikolajsen. Ida Schjødt is thanked for very good advice on flowcytometric analyses. We would also like to thank Eva Ehrnrooth for her help and good discussions.

\section{SUPPLEMENTARY MATERIAL}

The Supplementary Material for this article can be found online at: https://www.frontiersin.org/articles/10.3389/fimmu.2020. 595035/full\#supplementary-material

induces immunologic and clinical responses in multiple myeloma patients. Clin Cancer Res (2013) 19:3640-8. doi: 10.1158/1078-0432.CCR-13-0282

13. Ray A, Das DS, Song Y, Richardson P, Munshi NC, Chauhan D, et al. Targeting PD1-PDL1 immune checkpoint in plasmacytoid dendritic cell interactions with $\mathrm{T}$ cells, natural killer cells and multiple myeloma cells. Leukemia (2015) 29:1441-4. doi: 10.1038/leu.2015.11

14. Sponaas AM, Moharrami NN, Feyzi E, Standal T, Rustad EH, Waage A, et al. PDL1 expression on plasma and dendritic cells in myeloma bone marrow suggests benefit of targeted anti PD1-PDL1 therapy. PloS One (2015) 10: e0139867. doi: 10.1371/journal.pone.0139867

15. An G, Acharya C, Feng X, Wen K, Zhong M, Zhang L, et al. Osteoclasts promote immune suppressive microenvironment in multiple myeloma: therapeutic implication. Blood (2016) 128:1590-1603. doi: 10.1182/blood2016-03-707547

16. Paiva B, Azpilikueta A, Puig N, Ocio EM, Sharma R, Oyajobi BO, et al. PD$\mathrm{L} 1 / \mathrm{PD}-1$ presence in the tumor microenvironment and activity of PD-1 blockade in multiple myeloma. Leukemia (2015) 29:2110-3. doi: 10.1038/ leu.2015.79

17. Ishibashi M, Tamura H, Sunakawa M, Kondo-Onodera A, Okuyama N, Hamada Y, et al. Myeloma Drug Resistance Induced by Binding of Myeloma B7-H1 (PD-L1) to PD-1. Cancer Immunol Res (2016) 4:779-88. doi: 10.1158/ 2326-6066.CIR-15-0296

18. Crescenzi A, Annibali O, Bianchi A, Pagano A, Donati M, Grifoni A, et al. PD1/PD-L1 expression in extra-medullary lesions of multiple myeloma. Leuk Res (2016) 49:98-101. doi: 10.1016/j.leukres.2016.09.008

19. Gasmi B, Smith E, Dogan A, Hsu M, Devlin S, Pichardo J, et al. Presence of PD-1 Expressing $T$ Cells Predicts for Inferior Overall Survival in Newly Diagnosed Multiple Myeloma. ASH 2015 (abstract 1785) (2015). Available at: https://ash.confex.com/ash/2015/webprogram/Paper84149.html (Accessed 10th December 2015).

20. Tamura H, Ishibashi M, Yamashita T, Tanosaki S, Okuyama N, Kondo A, et al. Marrow stromal cells induce B7-H1 expression on myeloma cells, generating aggressive characteristics in multiple myeloma. Leukemia (2013) 27:464-472. doi: 10.1038/leu.2012.213

21. Lesokhin AM, Ansell SM, Armand P, Scott EC, Halwani A, Gutierrez M, et al. Nivolumab in Patients with Relapsed or Refractory Lymphoid Malignancy: Preliminary Results of a Phase I Study. J Clin Oncol (2016) 34:2698-704. doi: 10.1200/JCO.2015.65.9789

22. Usmani SZ, Schjesvold F, Oriol A, Karlin L, Cavo M, Rifkin RM, et al. Pembrolizumab plus lenalidomide and dexamethasone for patients with treatment-naive multiple myeloma (KEYNOTE-185): a randomised, openlabel, phase 3 trial. Lancet Haematol (2019) 6:e448-58. doi: 10.1016/s23523026(19)30109-7

23. Mateos M-V, Blacklock H, Schjesvold F, Oriol A, Simpson D, George A, et al. Pembrolizumab plus pomalidomide and dexamethasone for patients with relapsed or refractory multiple myeloma (KEYNOTE-183): a randomised, open-label, phase 3 trial. Lancet Haematol (2019) 6:e459-69. doi: 10.1016/ s2352-3026(19)30110-3 
24. van der Burg SH, Arens R, Ossendorp F, van Hall T, Melief CJM. Vaccines for established cancer: overcoming the challenges posed by immune evasion. Nat Rev Cancer (2016) 16:219-233. doi: 10.1038/nrc.2016.16

25. Chung DJ, Pronschinske KB, Shyer JA, Sharma S, Leung S, Curran SA, et al. Tcell Exhaustion in Multiple Myeloma Relapse after Autotransplant: Optimal Timing of Immunotherapy. Cancer Immunol Res (2016) 4:61-71. doi: 10.1158/2326-6066.CIR-15-0055

26. Svane IM, Nikolajsen K, Johnsen HE. Antigen-specific T-cell immunity in multiple myeloma patients is restored following high-dose therapy: implications for timing of vaccination. Scand J Immunol (2007) 66:465-75. doi: 10.1111/j.1365-3083.2007.01993.x

27. Williams KM, Hakim FT, Gress RE. T cell immune reconstitution following lymphodepletion. Semin Immunol (2007) 19:318-330. doi: 10.1016/ j.smim.2007.10.004

28. Gökbuget N, Canaani J, Nagler A, Bishop M, Kröger N. Avigan D.Prevention and treatment of relapse after stem cell transplantation with immunotherapy. Bone Marrow Transplant (2018) 53:664-72. doi: 10.1038/s41409-018-0232-3

29. Melief CJM, van der Burg SH. Immunotherapy of established (pre)malignant disease by synthetic long peptide vaccines. Nat Rev Cancer (2008) 8:351-60. doi: $10.1038 / \mathrm{nrc} 2373$

30. Ascarateil S, Puget A, Koziol M-E. Safety data of Montanide ISA 51 VG and Montanide ISA 720 VG, two adjuvants dedicated to human therapeutic vaccines. $J$ Immunother Cancer (2015) 3:2015. doi: 10.1186/2051-1426-3-S2-P428

31. Rajkumar SV, Harousseau JL, Durie B, Andersen KC, Dimopoulos M, Kyle R, et al. Consensus recommendations for the uniform reporting of clinical trials: report of the International Myeloma Workshop Consensus Panel 1. Blood (2011) 117:4691-5. doi: 10.1182/blood-2010-10-299487

32. de Vries IJM, Bernsen MR, Lesterhuis WJ, Scharenborg NM, Strijk SP, Gerritsen MJP, et al. Immunomonitoring tumor-specific T cells in delayedtype hypersensitivity skin biopsies after dendritic cell vaccination correlates with clinical outcome. J Clin Oncol (2005) 23:5779-87. doi: 10.1200/ JCO.2005.06.478

33. McCutcheon M, Wehner N, Wensky A, Kushner M, Doan S, Hsiao L, et al. A sensitive ELISPOT assay to detect low-frequency human T lymphocytes. J Immunol Methods (1997) 210:149-66. doi: 10.1016/S0022-1759(97) 00182-8

34. Moodie Z, Price L, Janetzki S, Britten CM. Response Determination Criteria for ELISPOT: Toward a Standard that Can Be Applied Across Laboratories. Methods Mol Biol (2012) 792:185-96. doi: 10.1007/978-1-61779-325-7_15

35. Yang B, Parsha K, Schaar K, Satani N, Xi X, Aronowski J, et al. Cryopreservation of Bone Marrow Mononuclear Cells Alters Their Viability and Subpopulation Composition but Not Their Treatment Effects in a Rodent Stroke Model. Stem Cells Int (2016) 2016:5876836. doi: 10.1155/2016/5876836

36. Garcia-Diaz A, Shin DS, Moreno BH, Saco J, Escuin-Ordinas H, Rodriguez GA, et al. Interferon Receptor Signaling Pathways Regulating PD-L1 and PD-L2 Expression. Cell Rep (2017) 19:1189-201. doi: 10.1016/j.celrep. 2017.04.031

37. Munir S, Lundsager MT, Jørgensen MA, Hansen M, Petersen TH, Bonefeld CM, et al. Inflammation induced PD-L1-specific T cells. Cell Stress (2019) 3:319-327. doi: 10.15698/cst2019.10.201
38. Iversen TZ, Engell-Noerregaard L, Ellebaek E, Andersen R, Larsen SK, Bjoern J, et al. Long-lasting disease stabilization in the absence of toxicity in metastatic lung cancer patients vaccinated with an epitope derived from indoleamine 2,3 dioxygenase. Clin Cancer Res (2014) 20:221-32. doi: 10.1158/1078-0432.CCR$13-1560$

39. Sørensen RB, Hadrup SR, Svane IM, Hjortsø MC, Straten PT. Andersen MH.Indoleamine 2,3-dioxygenase specific, cytotoxic $\mathrm{T}$ cells as immune regulators. Blood (2011) 117:2200-10. doi: 10.1182/blood-2010-06-288498

40. Andersen MH. The balance players of the adaptive immune system. Cancer Res (2018) 78:1379-1382. doi: 10.1158/0008-5472.CAN-17-3607

41. Danish Myeloma Study Group. Danish Myeloma Database. (2017). Available at www.myeloma.dk.

42. Gonsalves WI, Gertz MA, Dispenzieri A, Lacy MQ, Lin Y, Singh PP, et al. Implications of continued response after autologous stem cell transplantation for multiple myeloma. Blood (2013) 122:1746-49. doi: 10.1182/blood-201303-492678

43. Fernández De Larrea C, Dávila J, Isola I, Ocio EM, Rosinol L, García-Sanz R, et al. Absence of spontaneous response improvement beyond day +100 after autologous stem cell transplantation in multiple myeloma. Bone Marrow Transplant (2017) 52:567-9. doi: 10.1038/bmt.2016.299

44. Tran T, Blanc C, Granier C, Saldmann A, Tanchot C. Tartour E.Therapeutic cancer vaccine: building the future from lessons of the past. Semin Immunopathol (2018) 41:69-85. doi: 10.1007/s00281-018-0691-z

45. van der Burg SH. Correlates of immune and clinical activity of novel cancer vaccines. Semin Immunol (2018) 39:119-36. doi: 10.1016/j.smim.2018.04.001

Conflict of Interest: NJ: Research position is funded by The Danish Cancer Society; Copenhagen University Hospital, Herlev and Gentofte; and through a research funding agreement between IO Biotech ApS and National Center for Cancer Immune Therapy (CCIT-DK). MA: Author of a filed patent application based on the use of the PD-L1 peptide IO103 for vaccination. The patent rights have been transferred to Copenhagen University Hospital, Herlev, and Gentofte/ The Capital Region of Denmark, in accordance with the Danish Law of Public Inventions at Public Research Institutions. Additionally, the author is a shareholder and board member of the company IO Biotech ApS, which has the purpose of developing commercial PD-L1 vaccines for cancer treatment. IS: Cofounder and shareholder in IOBiotech Aps.

The remaining authors declare that the research was conducted in the absence of any commercial or financial relationships that could be construed as a potential conflict of interest.

Copyright (๑) 2020 Jørgensen, Klausen, Grauslund, Helleberg, Aagaard, Do, Ahmad, Olsen, Klausen, Breinholt, Hansen, Martinenaite, Met, Svane, Knudsen and Andersen. This is an open-access article distributed under the terms of the Creative Commons Attribution License (CC BY). The use, distribution or reproduction in other forums is permitted, provided the original author(s) and the copyright owner(s) are credited and that the original publication in this journal is cited, in accordance with accepted academic practice. No use, distribution or reproduction is permitted which does not comply with these terms. 